\title{
Avoiding the unintended consequences of climate change mitigation for African river basins
}

\section{Andrea Castelletti ( $\square$ andrea.castelletti@polimi.it)}

Politecnico di Milano https://orcid.org/0000-0002-7923-1498

\section{Matteo Giuliani}

Politecnico di Milano

\section{Jonathan Lamontagne}

Tufts University https://orcid.org/0000-0003-3976-1678

\section{Mohamad Hejazi}

Joint Global Change Research Institute Pacific Northwest National Laboratory

\section{Patrick Reed}

Cornell University https://orcid.org/0000-0002-7963-6102

\section{Research Article}

Keywords: African river basins, climate change, Water-Energy-Food (WEF) systems

Posted Date: August 14th, 2020

DOI: https://doi.org/10.21203/rs.3.rs-55222/v1

License: (c) (1) This work is licensed under a Creative Commons Attribution 4.0 International License. Read Full License

Version of Record: A version of this preprint was published at Nature Climate Change on January 31st, 2022. See the published version at https://doi.org/10.1038/s41558-021-01262-9. 

mitigation for African river basins

\author{
Matteo Giuliani ${ }^{1}$, Jonathan R. Lamontagne ${ }^{2}$, Mohamad I. Hejazi ${ }^{3}$, Patrick M. Reed ${ }^{4}$, Andrea \\ Castelletti ${ }^{1}$
}

(1) Department of Electronics, Information, and Bioengineering Politecnico di Milano, Milano, Italy.

(2) Department of Civil and Environmental Engineering, Tufts University, Medford, MA.

(3) Joint Global Change Research Institute, Pacific Northwest National Laboratory, College Park, MD.

(4) School of Civil and Environmental Engineering, Cornell University, Ithaca, NY.

Emerging climate change mitigation policies focus on the implementation of global measures relying on carbon prices to attain rapid emissions reductions, with limited consideration for the impacts of global policies at local scales. Here, we use the Zambezi River Basin in Southern Africa to demonstrate how local multisector dynamics across interconnected Water-Energy-Food (WEF) systems are impacted by global climate change mitigation policies. Our analysis provides quantitative evidence of the unintended vulnerabilities that emerge for this basin across a broad array of potential climate and socio-economic futures. Our results indicate that climate change mitigation policies related to land use change emissions can have negative side effects on local water demands, generating increased risks for failures across all the components of the WEF systems in the Zambezi River Basin. Analogous vulnerabilities could impact many river basins in Southern and Western Africa. It is critical to connect global climate change mitigation policies to local regional dynamics to better navigate the full range of possible future scenarios while supporting policy makers in prioritizing sustainable mitigation and adaptation solutions.

The 2015 Paris Agreement on Climate Change introduced ambitious global commitments to mitigate climate change and limit global temperature increase to $1.5-2^{\circ} \mathrm{C}$ above pre-industrial levels. Recent works suggest that achieving these targets will require immediate and rapid emissions reductions ${ }^{[1]}$, with promising emerging pathways that combine high carbon prices in the near term ${ }^{[2]}$ with the deployment of net negative emission technologies in the second half of the century ${ }^{[3]}$. Integrated Assessment Models (IAMs) are widely used to evaluate the efficacy and impact of these measures across a range of possible future scenarios ${ }^{[4,5,6]}$ that attempt to capture the complex interactions of energy, land-use, economic, water, and climate systems. These studies generally develop global [6] or regional analyses ${ }^{[7]}$ relying on economic abstractions of global welfare preferences, with less attention paid to the quantification of local scale impacts of abatement options for diverse groups of stakeholders with potentially conflicting needs or preferences ${ }^{[8]}$.

This paper addresses this gap by investigating how multisector dynamics across interconnected Water-Energy-Food systems at the local scale are impacted by global climate change mitigation policies. Our analysis uses a river basin-scale model of the Zambezi River in Southern Africa that enables exploration of synergies, tradeoffs, and vulnerabilities for the WEF systems including hydropower production, irrigation supply, and ecosystem services in one of the largest transboundary river basins in Africa as well as in the world. The rapid economic development of the region is increasing both energy and water demands, triggering major investments for hydropower development and the expansion of irrigated agriculture. These trends make the Zambezi River basin (ZRB) a paradigmatic example of most transboundary basins in developing countries that now must find a balance between social, economic, and environmental interests in order to promote development pathways that are inclusive as well as environmentally and economically sustainable [9].

Here, we consider a large ensemble of global scenarios simulated by the Global Change Analysis Model $\left(\mathrm{GCAM}^{[10]}\right)$, a model widely used in major integrated climate-energy-economic assessments $[11,12,13]$. To explore the uncertainty space, we adopt an exploratory modeling approach to systematically sample the Shared Socioeconomic Pathways (SSPS ${ }^{[14]}$ ) components along with 
multiple carbon prices and Shared Policy Assumptions (SPAs ${ }^{[15]}$ ), resulting in 33,750 scenarios ${ }^{[16]}$ (see Methods). Specifically, those scenarios include detailed, regionally specific and globally contextualized descriptions of population and economic growth, technological change, and climate change mitigation policy fragmentation drawn from the SSP/SPA implementation in GCAM ${ }^{[13]}$. The resulting scenario database contains tens of thousands of self-consistent, multi-sector, multi-scale, time-evolving scenarios of hundreds of climate, economic, demographic, and land use variables. We spatially and temporally downscale the GCAM outputs ${ }^{[17]}$ to generate projections of irrigation demands ${ }^{[18]}$. We also downscale climate projections for different Representative Concentration Pathways (RCPs, ${ }^{[19])}$ to force local hydrological models and produce projections of water availability. To ensure the consistency of the projected scenarios, we focus our analysis on an ensemble of scenarios that couple a projection of water availability driven by one RCP with a sub-set of projected irrigation demands based on the end-of-century radiative forcing as simulated by GCAM (see Methods). We first explore the synergies and tradeoffs across the WEF systems by analyzing a set of alternative adaptive operating policies for managing major reservoirs and irrigation diversions in the basin under observed climate and irrigation demands, showing that hydropower generation and irrigation supply are not strongly in conflict today. However, our projections suggest the ZRB will be exposed to severe risks of performance degradation across all the components of the WEF systems. Our results demonstrate these future vulnerabilities are mostly generated by global socio-economic drivers, namely the alternative land-use change policies, rather than predicted changes in water availability due to climate change. Analogous vulnerabilities are found across most basins in Southern and Western Africa, raising concerns about the equity of these global climate change mitigation policies for African countries.

\section{The WEF Nexus in river basins under development}

Africa has more than 60 international river basins that are a primary factor in the location and production patterns of human settlements as well as in the structure and productivity of African economies ${ }^{[20]}$. At the same time, African rivers, lakes, and wetlands are a major biodiversity reserve providing a large variety of ecosystem services, ranging from fishing and flood-recession agriculture to habitats for wildlife, migratory birds, and endemic species of global conservation concern ${ }^{[21]}$. In many countries, however, the accelerated population growth and the fast-economic development are motivating large-scale infrastructure investments to meet increasing water, energy, and food demands ${ }^{[22,23,24]}$. These projects may constitute a major threat to natural ecosystems and local subsistence needs ${ }^{[25]}$. In these evolving contexts, a major challenge to policy makers is navigating the tradeoffs of alternative development pathways between competing multisector dynamics, across different spatial scales, and over different time horizons including a broad array of potential climate, socio-techno-economic, and policy futures ${ }^{[26]}$.

The ZRB is a paradigmatic example of transboundary river basins under development. From the headwaters in northwest Zambia, the river flows eastward for $2,750 \mathrm{~km}$, also receiving water from the Kafue, Luangwa, and Shire rivers, draining a catchment area of 1.39 million $\mathrm{km}^{2}$ shared by eight countries (Figure 1). The basin provides services to a population of 40 million people, which is expected to grow rapidly up to 70 million by $2050^{[27]}$. The high runoff in the upper part of the basin combined with a change in elevation of more than $1000 \mathrm{~m}$ during its course to the ocean provide significant potential for hydropower energy production. The current installed capacity is about 5.5 TW, with an additional 8.4 TW planned by the end of $2023^{[28]}$. Around $70 \%$ of this installed capacity is concentrated in two megadams, namely Kariba (1,830 MW) and Cahora Bassa (2,075 MW). Existing irrigated areas cover about 182,000 ha with an annual water demand exceeding 6,300 $\mathrm{Mm}^{3} / \mathrm{y}$ (the average monthly demand is $200 \mathrm{~m}^{3} / \mathrm{s}$, with a peak close to $400 \mathrm{~m}^{3} / \mathrm{s}$ ), and the planned expansion will add other 336,000 ha ${ }^{[22]}$. Major cultivated crops are sugar cane $(23 \%)$, rice $(17 \%)$, wheat $(15 \%)$, and maize $(14 \%)^{[29]}$. The ZRB also provides numerous ecosystem services, which are being endangered by the development of hydropower and irrigated agriculture. These services include 82 key biodiversity areas ${ }^{[30]}$, numerous fisheries that represent the main source of proteins for the local rural communities, and tourism primarily to Victoria Falls and other national parks that generate around 10 million US\$/year ${ }^{[22]}$. Moreover, the basin comprises several wetlands of international importance, including an extensive alluvial plain in the Zambezi Delta covering 
approximatively 1.2 million ha ${ }^{[21]}$, where observed flows during the flooding season have been strongly reduced after the completion of Cahora Bassa with respect to the pre-dam conditions ${ }^{\text {[31] }}$. This trend is expected to further worsen because of the planned dam construction and irrigated agriculture expansions.

\section{Future vulnerabilities across the WEF systems}

Given the ZRB model and the local objectives for the WEF systems defined in collaboration with local stakeholders (see Methods), we first perform a multisectoral analysis on a set of 120 alternative operating policies for managing existing reservoirs and irrigation diversions that capture the optimal tradeoffs (i.e., Pareto efficient ${ }^{[32]}$ ) across their competing multi-sectoral demands over historically observed conditions. Each Pareto-optimal control solution represents a different balance of compromises across the WEF objectives (Supplementary Figure S1). The maximization of the hydropower production negatively impacts environmental conditions in the Delta (Supplementary Figure S2), while the tradeoff between energy and irrigation supply is weak. As was shown by others [33], our analysis suggests that the system's historical operations emphasize the maximization of hydropower production, under which existing irrigation demands are mostly satisfied. Yet, a key question is whether multi-sector resource conflicts may become more severe in future scenarios that have either climate induced decreases in water availability, population driven increases in irrigation demand, an intensification of agricultural activities in the region, or a combination of the three.

To investigate the future vulnerabilities of the modeled historical operations of the ZRB system to these water availability conflicts, we sample six socio-economic uncertainties as represented in the SSPs and simulated using GCAM (see Methods). Those socio-economic uncertainties were paired with three climate projections corresponding to downscaled and bias-adjusted RCP2.6, RCP4.5, and RCP8.5 scenarios. To ensure consistency between the socio-economic and climate scenarios, the coupling was performed based on the 2100 forcing projected within GCAM. This coupling resulted in an ensemble of 2,439 interdependent scenarios (see Methods and Supplementary Figure S3 for details). For each RCP, the differences in the underlying irrigation demands introduce large variability in system performance. Hydropower production (Figure 2a) appears mostly driven by the projected decreases in water availability, with the distributions of the estimated production under RCP2.6 and RCP4.5 that mostly lie in the range of $35 \%$ to $50 \%$ decrease relative to the historical production, while registering a decrease larger than $50 \%$ in more than half of the scenarios under RCP8.5. The simulated values of irrigation deficit (Figure $2 b$ ) remain lower than $177 \mathrm{~m}^{3} / \mathrm{s}$ (i.e., twice the historical performance) for about $16 \%$ of the demand scenarios in all the RCPs. Acting on the demand side is therefore paramount for ensuring a reliable irrigation supply across diverse scenarios of water availability. Conversely, the worst-case performance is largely dependent on the climate conditions, with significantly higher deficits under RCP8.5 (i.e., 8 times larger than the historical value) than under the other two climate scenarios. Lastly, the projected performance in terms of environmental deficit (Figure 2c) shows an overall worsening of about 35\% with respect to the performance under historical conditions across all scenarios, with the simulated values of flow deficits that correspond to about one third of the flow target in the ZRB Delta. Interestingly, the distributions clearly separate with respect to the RCP scenarios. However, despite this objective is a function of the water flowing into the Delta, the distributions are not ordered according to the predicted annual flow entering the river basin. The best performance is indeed obtained under RCP2.6, but the worst performance is obtained under RCP4.5, the climate scenario with the highest projected natural water availability.

\section{Discovering the global drivers of local vulnerabilities}

The unexpected vulnerability of the environment in the ZRB Delta (Figure 2a), despite high annual flow, suggests that the socio-economic scenarios associated with the RCP4.5 climate projection play a major role determining the future system dynamics. To infer the key controls of such dynamics, the scatterplot in Figure 3a explores the simulated growth of the irrigation demands in Southern Africa for three alternative policies of Land Use Change (LUC) emissions prices. Our results show that the LUC prices, beside impacting the level of GHG emissions and the resulting end of century 
radiative forcing, generate three distinct clusters of irrigation demands. Scenarios with no emissions price of any kind result in values of radiative forcing in the range $6-10 \mathrm{~W} / \mathrm{m}^{2}$ that are associated to the RCP8.5 scenario (red lines in Figure 2), with an average projected irrigation demand increase of about $300 \%$. The application of a price on emissions successfully contains the radiative forcing below $7 \mathrm{~W} / \mathrm{m}^{2}$, with many of these scenarios that are hence compatible with the RCP4.5 climate projections (green lines in Figure 2). The scenarios with the lowest 2100 forcing are instead associated to the RCP2.6 scenario (blue lines in Figure 2). Scenarios with LUC emissions prices do not significantly impact the overall end-of-century radiative forcing, but we found they can have significant impact on regional land-use changes. We tested two cases: a fragmented and a universal LUC price (roughly consistent with SPAs 4 and 2 respectively). In the fragmented case, wealthy countries make strong attempts to curb LUC emissions, as represented by a high LUC emissions price, while developing countries have limited LUC policies represented by a lower LUC emissions price. The heterogeneity of this global policy generates favorable conditions for land grabbing practices ${ }^{[34]}$, with wealthy countries investing in the realization of extensive agricultural projects (e.g., large scale, intensive irrigation projects similar to the existing Mazabuka district). Under the fragmented LUC price, irrigation demand in Southern Africa (where the LUC emissions price is low) increases up to $700 \%$ due to extensive agricultural LUC. Conversely, the same scenarios under the universal LUC price, representing a unified approach to LUC policy, experience irrigation demand increases that do not exceed $300 \%$, with virtually the same radiative forcing.

The scatterplot in Figure 3b supports this hypothesis by showing that the universal LUC price produces a similar increase in irrigation demands between the Southern Africa region and the rest of the world. The fragmented LUC price, instead, introduces diverse trends with an increase in the Southern Africa region that is much larger than the global one. These very high demand scenarios explain the divergent distributions of the irrigation deficit under RCP2.6 and RCP4.5 (Figure 2b) which have similar conditions in terms of projected natural water availability. Moreover, high demands imply large water abstractions to serve the irrigation districts along the Zambezi River that reduce the water flowing into the Delta. This practice negatively impacts on the ecosystem services provided by the Zambezi River Delta (Figure 2c), showing how the impact of future socio-economic conditions may offset the one of the projected climate conditions.

\section{Discussion and Conclusions}

Our study indicates that global climate change mitigation policies can have side effects on local water demands. Containing GHG emissions and the resulting end of century radiative forcing may increase the natural water availability in a river basin but does not necessarily result in better system performance. We find that the water-energy-food systems in the ZRB are exposed to severe risks of performance degradation that are mostly generated by global socio-economic drivers, notably the alternative policies of land-use change prices. Since the ZRB is paradigmatic of many river basins where large dams are planned to support growing economies, we expect our findings to be generalizable to several other African regions.

In our scenarios, the average continental increase of end of century irrigation demands relative to 2005 is equal to $140 \%$, with diverse trends across the five African regions ranging from $395 \%$ and $152 \%$ increases in Southern and Northern Africa, respectively, to a $30 \%$ decrease in Eastern Africa (see Supplementary Figure S6). Notably, the demand increase under fragmented LUC emission price is about two times larger than under universal LUC price for both the Southern and Western Africa regions (Figure 4). These two regions also include about $60 \%$ of all African dams currently planned or under construction ${ }^{[35]}$. These features suggest that both regions are expected to be exposed to increasing local demands and vulnerabilities comparable to the ones illustrated for the ZRB case, that might be unintentionally underestimated by ignoring large-scale socio-economic dynamics in the attempt of enhancing the accuracy of local scale models ${ }^{[6]}$. At the same time, decoupling water demands from the analysis of global climate policies could misrepresent local multisector dynamics, not only in terms of projected water demands but also for electricity capacity expansion ${ }^{[37]}$. 
We should therefore better understand the tradeoff between targeting realism at the micro scale and representing global socio-economic teleconnections to be able to explore the full range of possible future scenarios ${ }^{[38]}$ when supporting policy makers in prioritizing mitigation and adaptation strategies across different spatial scales. Our finding highlights how well-intentioned climate change mitigation policies introduced in wealthier countries could have the unintended consequence of increasing vulnerabilities in river basins throughout the developing world. To avert these negative effects, policy makers may have to look beyond their own boarders to avoid water-use outsourcing and to ensure environmental and climate justice for all ${ }^{[39,40]}$.

\section{References}

[1] J. Lamontagne, P. Reed, G. Marangoni, K. Keller and G. Garner, "Robust abatement pathways to tolerable climate futures require immediate global action," Nature Climate Change, vol. 9, no. 4, pp. 290-294, 2019.

[2] G. Luderer, Z. Vrontisi, C. Bertram, O. Y. Edelenbosch, R. C. Pietzcker, J. Rogelj, H. S. D. Boer, L. Drouet, J. Emmerling, O. Fricko, S. Fujimori, P. Havlík, G. Iyer, K. Keramidas and A. Kitous, "Residual fossil CO2 emissions in 1.5-2 C pathways," Nature Climate Change, vol. 8, no. 7, pp. 626-633, 2018.

[3] D. van Vuuren, A. Hof, M. van Sluisveld and K. Riahi, "Open discussion of negative emissions is urgently needed," Nature Energy, vol. 2, pp. 902-904, 2017.

[4] S. Santos Da Silva, F. Miralles-Wilhelm, R. Muñoz-Castillo, L. E. Clarke, C. J. Braun, A. Delgado, J. A. Edmonds, M. Hejazi, J. Horing, R. Horowitz, P. Kyle, R. Link, P. Patel, S. Turner and McJeon, "The Paris pledges and the energy-water-land nexus in Latin America: Exploring implications of greenhouse gas emission reductions," PLoS One, vol. 14, no. 4, 2019.

[5] S. Fujimori, T. Hasegawa, V. Krey, K. Riahi, C. Bertram, B. Leon Bodirsky, V. Bosetti, J. Callen, J. Després, J. Doelman, L. Drouet, J. Emmerling, S. Frank and Fricko, "A multimodel assessment of food security implications of climate change mitigation," Nature Sustainability, vol. 2, pp. 386-396, 2019.

[6] J. Rogelj, D. McCollum, B. O'Neill and K. Riahi, "2020 emissions levels required to limit warming to below $2^{\circ} \mathrm{C}$," Nature Climate Change, vol. 3, no. 4, pp. 405-412, 2013.

[7] M. Tavoni, E. Kriegler, K. Riahi, D. Van Vuuren, T. Aboumahboub, A. Bowen, K. Calvin, E. Campiglio, T. Kober, J. Jewell, G. Luderer, G. Marangoni, D. McCollum, M. van Sluisveld and A. Zimmer, "Post-2020 climate agreements in the major economies assessed in the light of global models," Nature Climate Change, vol. 5, no. 2, pp. 119-126, 2015.

[8] G. Garner, P. Reed and K. Keller, "Climate risk management requires explicit representation of societal trade-offs," Climatic Change, vol. 134, pp. 713-723, 2016.

[9] J. Dearing, R. Wang, K. Zhang, J. Dyke, H. Haberl, M. Hossain, P. Langdon, T. Lenton, K. Raworth, S. Brown, J. Carstensen, M. Cole, S. E. Cornell, T. Dawson, C. Doncaster, F. Eigenbrod, M. Flörke, E. Jeffers and A. Mackay, "Safe and just operating spaces for regional social-ecological systems," Global Environmental Change, vol. 28, pp. 227-238, 2014.

[10] Joint Global Change Research Institute, "GCAM v4.3 documentation: Global change assessment model (GCAM)," JGCRI, 2017.

[11] A. Thomson, K. Calvin, S. Smith, G. Kyle, A. Volke, P. Patel and J. Edmonds, "RCP4.5: A pathway for stabilization of radiative forcing by 2100 ," Climatic Change, vol. 109, no. 1-2, pp. 77-94, 2011.

[12] L. Clarke, K. Jiang, K. Akimoto, M. Babiker, G. Blanford, K. Fisher-Vanden, J.-C. Hourcade, V. Krey, E. Kriegler, A. Löschel, D. McCollum, S. Paltsev, S. Rose, P. R. Shukla and Tavoni, "Assessing transformation pathways," in Climate Change 2014: Mitigation of Climate Change, Fifth Assessment Report of the Intergovernmental Panel on Climate Change, New York, NY, Cambridge University Press, 2014. 
[13] K. Calvin, B. Bond-Lamberty, L. Clarke, J. Edmonds, J. Eom, C. Hartin, S. Kim, P. Kyle, R. Link, R. Moss, H. McJeon, P. Patel, S. Smith, S. Waldhoff and M. Wise, "The SSP4: A world of deepening inequality," Global Environmental Change, vol. 42, pp. 284-296, 2017.

[14] D. van Vuuren, K. Riahi, K. Calvin, R. Dellink, J. Emmerling, S. Fujimori, S. KC, E. Kriegler and B. O'Neill, "The Shared Socio-economic Pathways: Trajectories for human development and global environmental change," Global Environmental Change, vol. 42, pp. 148-152, 2017.

[15] E. Kriegler, J. Edmonds and S. Hallegatte, "A new scenario framework for climate change research: the concept of shared climate policy assumptions," Climatic Change, vol. 122, pp. 401-414, 2014.

[16] J. Lamontagne, P. Reed, R. Link, K. Calvin, L. Clarke and J. Edmonds, "Large Ensemble Analytic Framework for Consequence-Driven Discovery of Climate Change Scenarios," Earth's Future, p. 488- 504, 2018.

[17] X. Li, C. Vernon, M. Hejazi, R. Link, Z. Huang, L. Liu and L. Feng, "Tethys-A Python Package for Spatial and Temporal Downscaling of Global Water Withdrawals," Journal of Open Research Software, vol. 6, 2018.

[18] Z. Huang, M. Hejazi, Q. Tang, C. Vernon, Y. Liu, M. Chen and K. Calvin, "Global agricultural green and blue water consumption under future climate and land use changes," Journal of Hydrology, vol. 574, pp. 242-256, 2019.

[19] D. van Vuuren, J. Edmonds, M. Kainuma, K. Riahi, A. Thomson, K. Hibbard, G. Hurtt, T. Kram, V. Krey, J. Lamarque, T. Masui, M. Meinshausen, N. Nakicenovic, S. Smith and S. Rose, "The representative concentration pathways: an overview," Climatic Change, vol. 109, no. 5, 2011.

[20] C. Sadoff, D. Whittington and D. Grey, Africa's international rivers: an economic perspective, Washington, D.C.: The World Bank, 2003.

[21] R. Beilfuss, "Zambezi River Delta (Mozambique)," in The Wetland Book, M. G. P. R. D. N. Finlayson C., Ed., Dordrecht, Springer, 2016.

[22] World Bank, "The Zambezi River Basin. A Multi-Sector Investment Opportunities Analysis," World Bank, Washington, DC, 2010.

[23] M. Jeuland and D. Whittington, "Water resources planning under climate change: Assessing the robustness of real options for the Blue Nile," Water Resources Research, vol. 50, no. 3, pp. 2086-2107, 2014.

[24] J. J. S. Warner, E. Jones, M. Ansari and L. De Vries, "The Fantasy of the Grand Inga Hydroelectric Project on the River Congo," Water, vol. 11, no. 3, p. 407, 2019.

[25] K. Winemiller, P. Mcintyre, L. Castello, E. Fluet-Chouinard, T. Giarrizzo, S. Nam, I. G. Baird, W. Darwall, N. K. Lujan, I. Harrison, M. L. Stiassny, R. A. Silvano, D. B. Fitzgerald, F. M. Pelicice, A. A. Agostinho, L. C. Gomes and Al, "Balancing hydropower and biodiversity in the Amazon, Congo, and Mekong," Science, Vols. 351(6269),, no. 6269, pp. 128-129., 2016.

[26] D. Conway, E. van Garderen, D. Deryng, S. Dorling, T. Krueger, W. Landman, B. Lankford, K. Lebek, T. Osborn, C. Ringler, J. Thurlow, T. Zhu and C. Dalin, "Climate and southern Africa's water-energy-food nexus," Nature Climate Change, vol. 5, no. 9, pp. 837-846, 2015.

[27] SADC, ZAMCON and SARDC, "Zambezi Environmental Outlook," Harare, Gaborone, 2015.

[28] R. Cervigni, R. Liden, J. Neumann and K. Strzepek, "Enhancing the Climate Resilience of Africa's Infrastruc- ture: The Power and Water Sectors," World Bank, Washington, DC, 2015.

[29] R. Payet-Burin, M. Kromann, S. Pereira-Cardenal, K. Strzepek and P. Bauer-Gottwein, "WHAT-IF: An open-source decision support tool for water infrastructure investment planning within the water-energy-food-climate nexus," Hydrology and Earth System Sciences, vol. 23, no. 10, pp. 4129-4152, 2019.

[30] BirdLife International, "World Database of Key Biodiversity Areas," 2018. [Online]. Available: www.keybiodiversityareas.org. [Accessed 201808 07]. 
[31] R. Beilfuss and D. dos Santos, "Patterns of hydrological change in the Zambezi Delta, Mozambique," in Program for the Sustainable Management of Cahora Bassa Dam and the Lower Zambezi Valley, 2001.

[32] C. Coello Coello, G. Lamont and D. V. Veldhuizen, Evolutionary Algorithms for Solving MultiObjective Problems, New York, NY: Springer, 2007.

[33] A. Tilmant, L. Beevers and B. Muyunda, "Restoring a flow regime through the coordinated operation of a multireservoir system: The case of the Zambezi River basin," Water Resources Research, vol. 46, 2010.

[34] M. Rulli, A. Saviori and P. D'Odorico, "Global land and water grabbing," Proceedings of the National Academy of Sciences, vol. 110, no. 3, pp. 892-897, 2013.

[35] C. Zarfl, A. Lumsdon, J. Berlekamp, L. Tydecks and K. Tockner, "A global boom in hydropower dam construction," Aquatic Sciences, vol. 77, pp. 161-170, 2015.

[36] N. Graham, M. Hejazi, M. Chen, E. Davies, J. Edmonds, S. Kim, S. W. Turner, X. Li, C. R. Vernon, K. Calvin, F. Miralles-Wilhelm, L. Clarke, P. Kyle, R. Link, P. Patel, A. C. Snyder and $M$. Wise, "Humans drive future water scarcity changes across all Shared Socioeconomic Pathways," Environmental Research Letters, vol. 15, no. 1, 2020.

[37] L. Liu, M. Hejazi, G. Iyer and B. Forman, "Implications of water constraints on electricity capacity expansion in the United States," Nature Sustainability, vol. 2, no. 3, pp. 206-213, 2019.

[38] D. McCollum, A. Gambhir, J. Rogelj and C. Wilson, "Energy modellers should explore extremes more systematically in scenarios," Nature Energy, vol. 5, no. 2, pp. 104-107, 2020.

[39] D. Schlosberg and L. Collins, "From environmental to climate justice: climate change and the discourse of environmental justice," Wiley Interdisciplinary Reviews: Climate Change, vol. 5, no. 3, pp. 359-374, 2014.

[40] N. Taconet, A. Méjean and C. Guivarch, "Influence of climate change impacts and mitigation costs on inequality between countries," Climatic Change, pp. 1-20, 2020. 


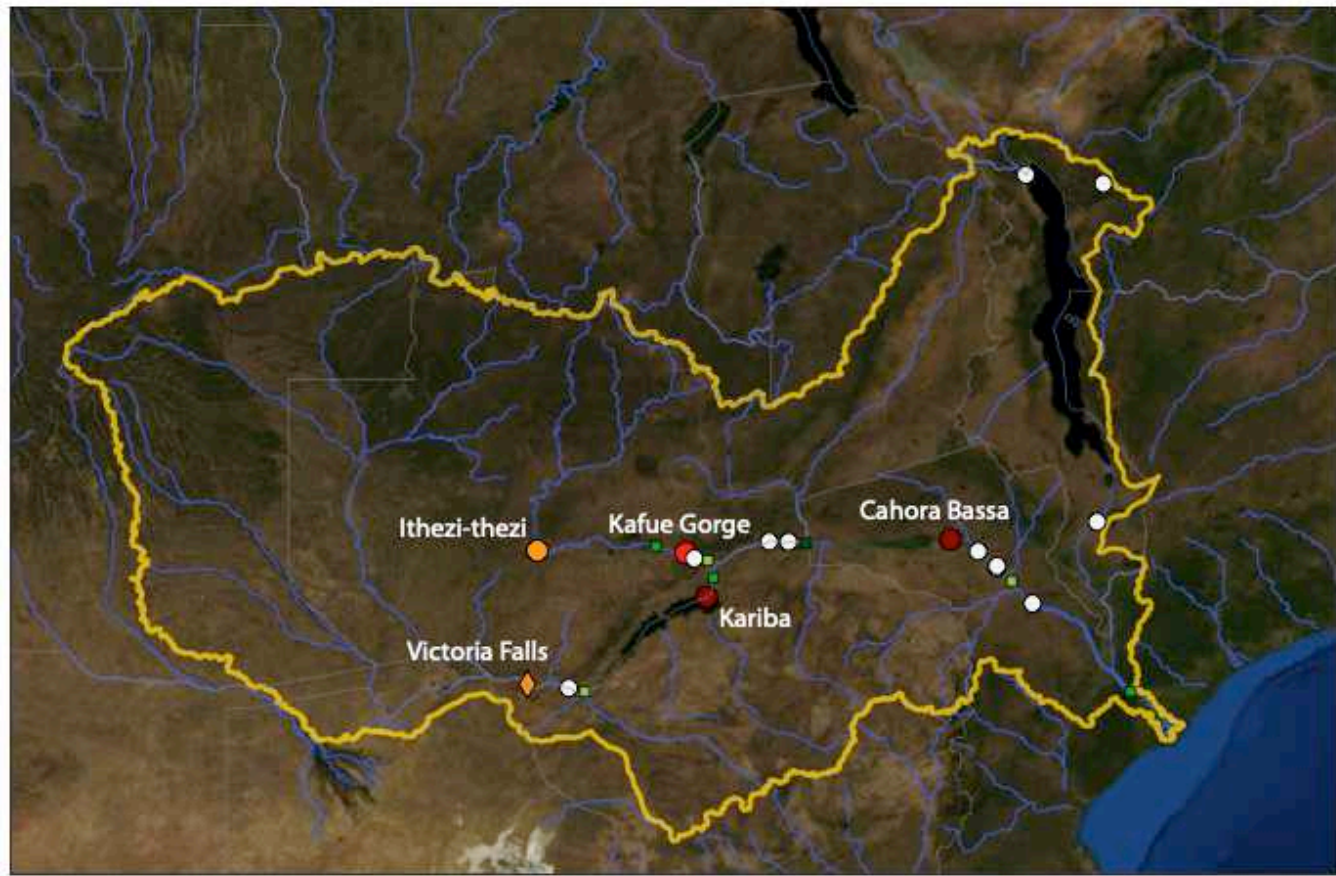

Hydropower plants

- Existing Storage

O Planned Storage

$\diamond$ Run-of-the-river

Installed Capacity

- 100-500 MW

- 501-1500 MW

- $1501-2500 \mathrm{MW}$

Irrigation districts

- $1-10 \mathrm{~m}^{3 / 5}$

- $11-50 \mathrm{~m}^{3 / \mathrm{s}}$

. $51-100 \mathrm{~m}^{3 / \mathrm{s}}$

Figure 1: Locations of dams and irrigation districts in the Zambezi River basin. Four dams and six power plants are currently in operations for a total installed capacity of 5,500 MW, while existing irrigated areas cover about 182,000 ha. Planned hydropower reservoirs will provide $8,400 \mathrm{MW}$ of additional power capacity. 
a

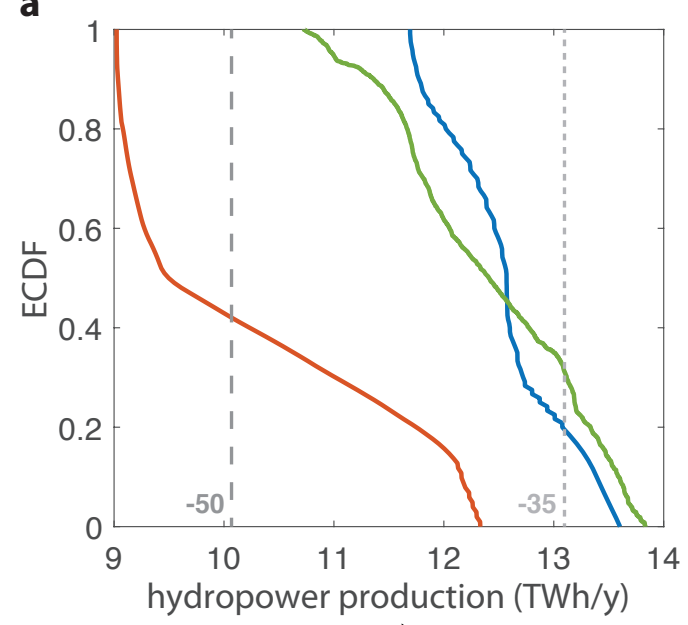

c

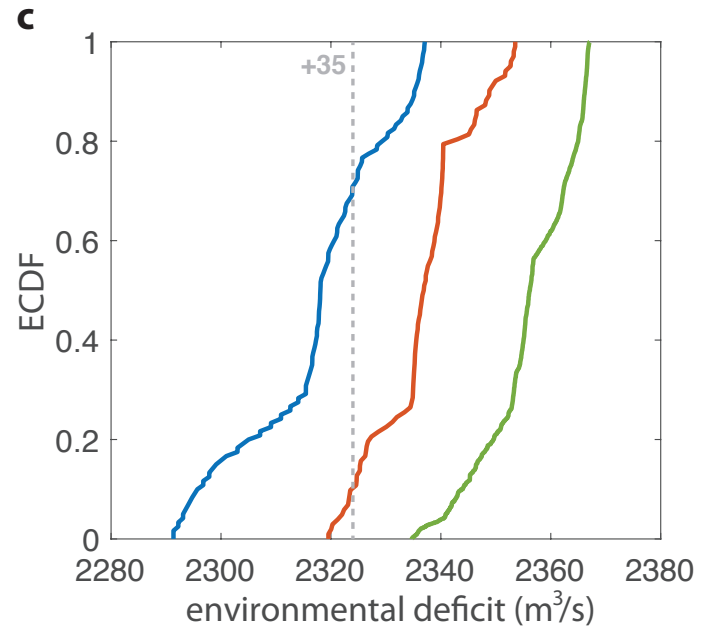

b

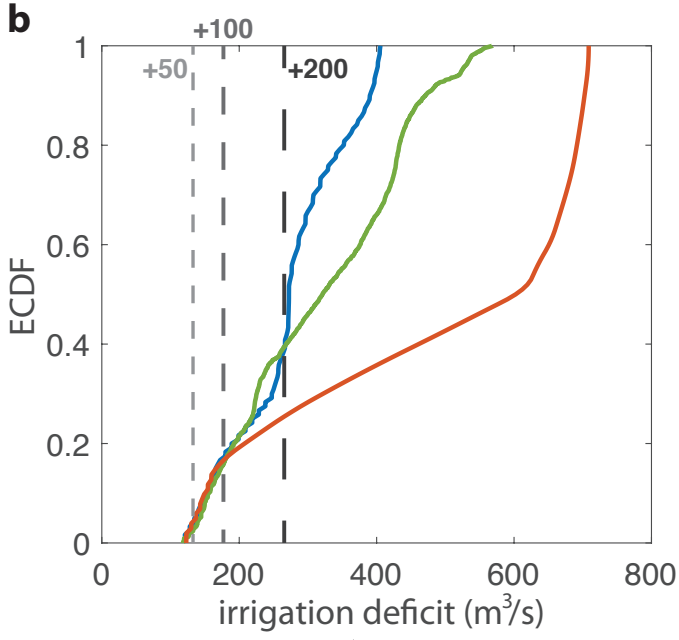

Performance change relative to historical period

\begin{tabular}{|c|c|c|c|}
\hline $\begin{array}{c}\text { relative } \\
\text { change (\%) }\end{array}$ & $\begin{array}{c}\text { hydropower } \\
\text { production }(\mathrm{TWh} / \mathrm{y})\end{array}$ & $\begin{array}{c}\text { irrigation } \\
\text { deficit }\left(\mathrm{m}^{3} / \mathrm{s}\right)\end{array}$ & $\begin{array}{c}\text { environmental } \\
\text { deficit }\left(\mathrm{m}^{3} / \mathrm{s}\right)\end{array}$ \\
\hline-750 & -7.06 & & +602 \\
\hline----50 & -10.08 & +44.25 & \\
\hline---100 & & +88.5 & \\
\hline---200 & & +177 & \\
\hline
\end{tabular}

Climate scenarios

- RCP2.6 $\left(20,368 \mathrm{~m}^{3} / \mathrm{y}\right)$ RCP4.5 $\left(20,503 \mathrm{~m}^{3} / \mathrm{y}\right)$ $\operatorname{RCP} 8.5\left(17,618 \mathrm{~m}^{3} / \mathrm{y}\right)$

Figure 2: Future system vulnerabilities. Empirical Cumulative Distribution Functions of the uncertain attainment of the local ZRB objectives estimated via simulation of the modeled historical ZRB operations over the ensemble of interdependent climate and socio-economic scenarios (hydropower production (a), irrigation deficit (b), and environmental deficit (c), while the variance objective is not shown due to its limited sensitivity to the considered scenarios). Black arrows indicate the direction of increasing preference for each objective. The color of the ECDF lines marks the different climate scenarios; values in brackets report the projected average annual flow entering the river basin. The dashed vertical lines represent the degradation of performance relative to the historical one (see Supplementary Figure S1). 
a

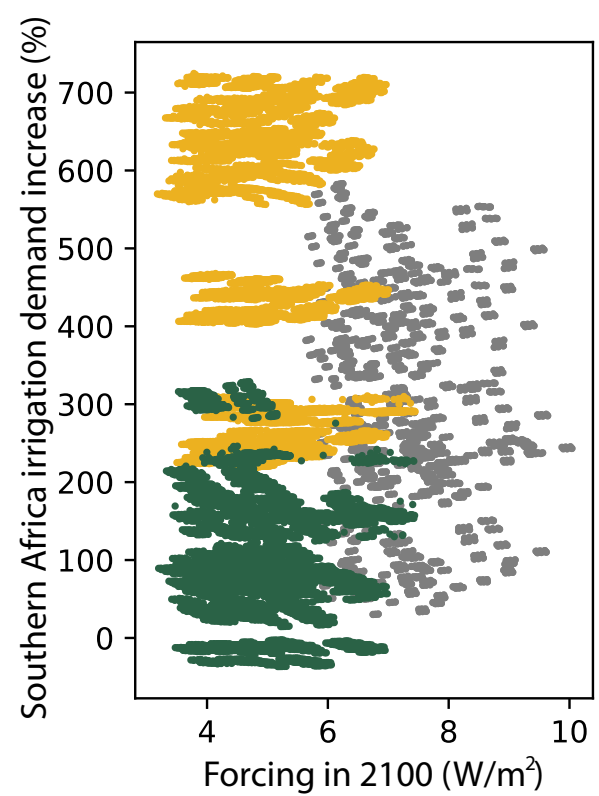

b

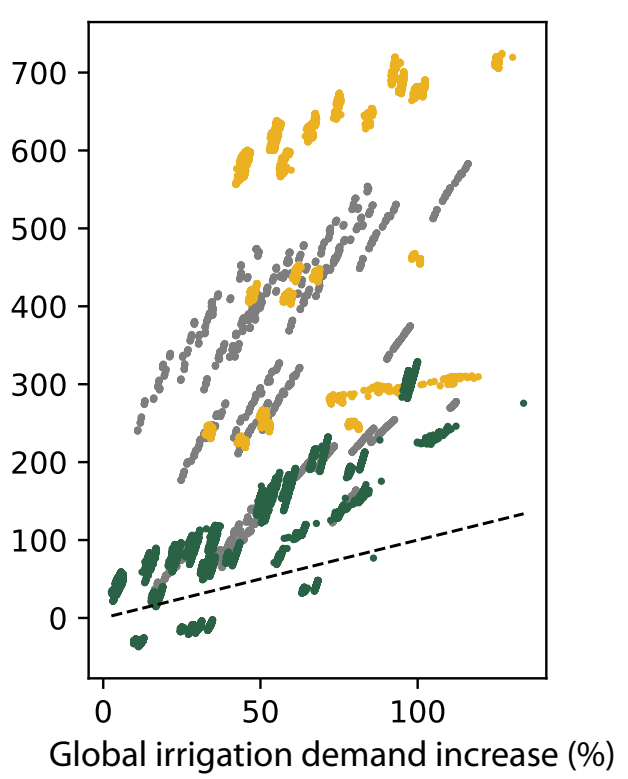

Figure 3: Analysis of socio-economic scenarios generated by GCAM. a, Scatterplot between end of century radiative forcing and irrigation demand growth relative to 2005 for the Southern Africa region. b, Scatterplot between global and Southern Africa irrigation demand growth relative to 2005 (the black dashed line is the 1:1 reference). Colors represent alternative policies of Land Use Change (LUC) emission price: gray points are scenarios with no emission price, green with universal LUC price, and yellow with fragmented LUC price (i.e., wealthy countries pay a higher LUC emission price than developing ones due to their strong attempts to curb LUC emission). 


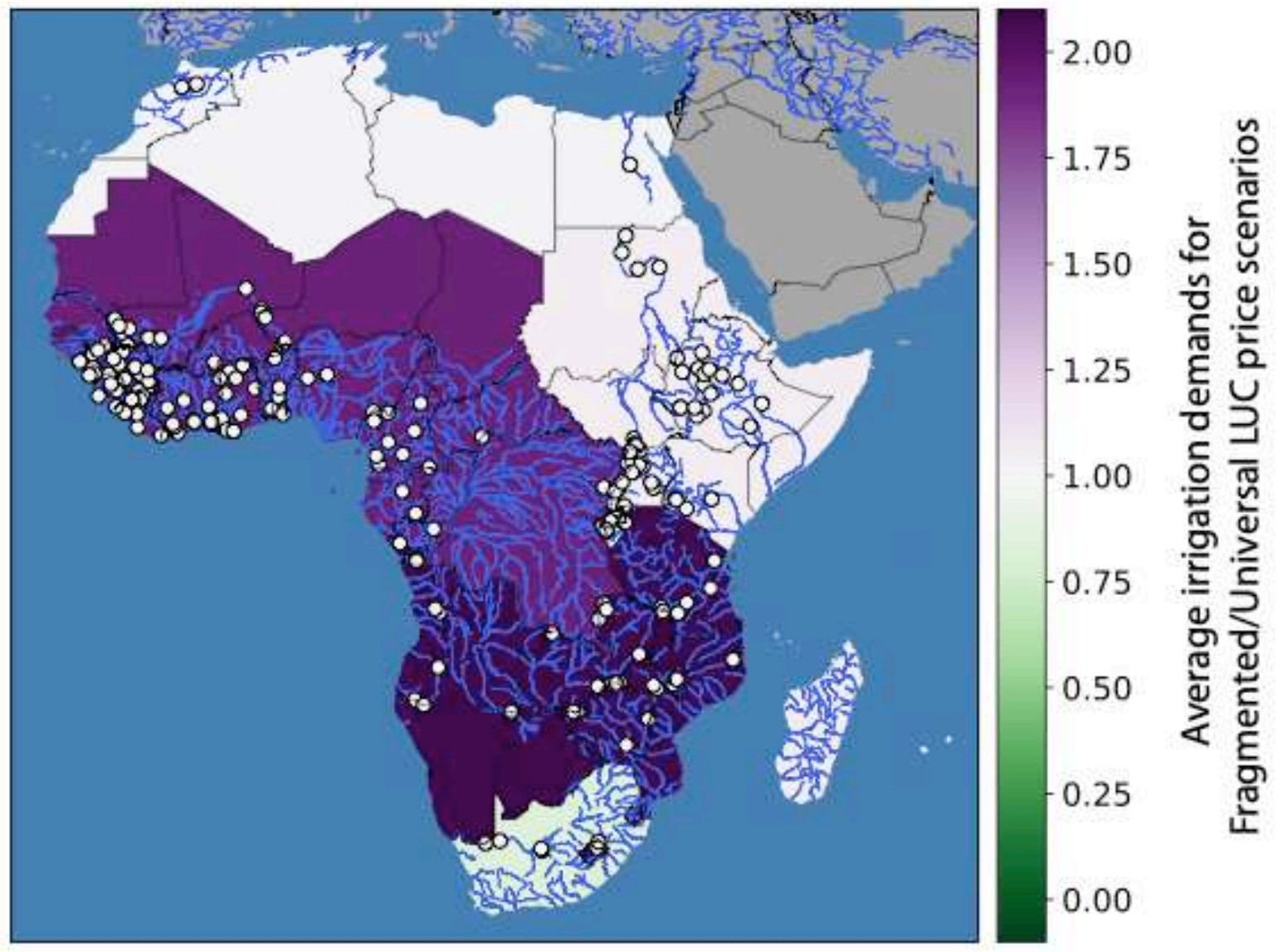

Figure 4: Projected vulnerabilities of African regions. The map shows African countries colored according to the ratio of average 2005-2100 irrigation demands projected by GCAM for scenarios with fragmented LUC price over the one of scenarios with universal LUC price. The white circles indicate the locations of future hydropower reservoirs and dams extracted from ${ }^{[35]}$. 


\section{Zambezi River Basin model}

The model of the Zambezi River Basin relies on a combination of conceptual and data-driven models, including the hydrologic model of the sub-catchments, the dynamic model of the reservoirs, and the irrigation diversions serving the agricultural districts located along the river.

The Ithezithezi, Victoria Falls, and Luangwa sub-basins are represented through the conceptual hydrologic model Hydrologiska Byrans Vattenbalansavdelning (HBV) ${ }^{[41]}$, which simulate the soil water balance and subsequent rainfall-runoff processes. The models were calibrated over the time period 1981-1998 and validated over the 1998-2006 (in the case of Luangwa the periods 1981-1990 and 1996-2001 were used due to the presence of several gaps in the available timeseries). The average NSE in validation for the three HBV models is equal to 0.75 .

The Shire sub-basin, which includes also Lake Malawi, is modeled by means of a data-driven artificial neural network reproducing the net inflows to the lake (i.e., inflows minus evaporation losses) coupled with a mass-balance equation reproducing the lake dynamics. The NSE of the combined model is equal to 0.63 .

Precipitation data are taken from the Climate Hazard Group InfraRed Precipitation with Station (CHIRPS) gridded dataset ${ }^{[42]}$, which provides daily timeseries starting in 1981 with a spatial resolution of $0.05^{\circ}$. Temperature data are instead taken from Observational Reanalysis Hybrid (OHR) gridded dataset, which provides daily timeseries of minimum and maximum temperature from 1981 to 2005 with a spatial resolution of $0.1^{\circ}[43]$. Lastly, streamflow data are taken from the ADAPT dataset ${ }^{[44]}$ using the following gauging stations: Kafue Hook Bridge, Victoria Falls IN, Great East Road Bridge, and Mangochi.

The monthly dynamics of the main reservoirs, namely Ithezhi-tezhi, Kafue Gorge, Kariba, and Cahora Bassa is described by the mass balance of the water volume stored in each reservoir. The release volume is determined by a nonlinear, stochastic function that depends on the release decision ${ }^{[45]}$. This function allows representing the effect of the uncertain inflows between the time at which the decision is taken (i.e., beginning of each month) and the time at which the release is completed (i.e., end of the month). The actual release might indeed not be equal to the decision due to existing legal and physical constraints on the reservoir level and release, including spills when the reservoir level exceeds the maximum capacity.

According to the monthly time-step of the model, the river reaches are modelled as plug-flow canals with negligible travel time and without any lamination effect. An exception is made for the Kafue Flats, an extensive floodplain where the river flows slowly for $250 \mathrm{~km}$ taking about two months from Ithezi-thezi reach Kafue Gorge. Minimum environmental flow constraints protect the ecosystems at Victoria Falls and in the Kafue Flats: the diversion to the Victoria Falls power plant should ensure $250 \mathrm{~m}^{3} / \mathrm{s}$ in the mainstream; the releases from Ithezi-thezi should guarantee a streamflow equal to $40 \mathrm{~m}^{3} / \mathrm{s}\left(315 \mathrm{~m}^{3} / \mathrm{s}\right.$ in March) in the Kafue Flats ${ }^{[31]}$.

The four reservoirs are connected to an associated hydropower plant. In addition, a run-of-the-river hydropower plant is in operation at Victoria Falls. The total installed capacity is $5.12 \mathrm{GW}$. The 7 agricultural districts are characterized by time-varying irrigation demands associated to a corresponding diversion channel that is regulated by a non-linear hedging rule ${ }^{[46]}$. The historical water demands are taken from ${ }^{[22]}$, which specifies also the cultivated crops (i.e., mostly wheat and maize, except for the districts along the Kafue River that cultivates sugarcane) and the irrigation districts area is retrieved from the Global Map of Irrigation Areas by FAO AQUASTAT, which reports the areas equipped with irrigation in 2005 over a grid with spatial resolution of $0.083^{\circ}$.

Different objective functions representing the three components of the Water-Energy-Food Nexus were formulated though a participatory process involving key stakeholders active in the system, that 
participated in dedicated meetings called Negotiation Simulation Labs held during the DAFNE research project.

The Water component of the Nexus is associated to the protection of the ecosystems in the Zambezi River Delta and is formulated as the environmental deficit with respect to the target pulse of 7,000 $\mathrm{m}^{3} / \mathrm{s}$ during the peak flow season in February and March ${ }^{[21,33]}$. The Energy component of the Nexus is related to the total hydropower production obtained as the sum of the production in all the modeled hydropower plants. According to the Zambezi River Basin master plan ${ }^{[47]}$ and considering that all these power plants are connected to the Southern African Power Pool, the hydropower production is measured at the basin-wide scale, thus neglecting national strategies. The Food component of the Nexus is captured by two distinct objectives: the first is the irrigation deficit, considered as a proxy for the food production, which formulated as the total average water supply deficit over all the irrigation districts; the second is the variance of the average squared water supply deficits across the districts to avoid unbalanced water allocations.

The coordinated operation of the four reservoirs and 7 diversion channels is determined by a closedloop operating policy ${ }^{[48]}$ that depends on the month of the year, the four reservoir storages, and the total previous month inflow. This allows simulating sequences of control actions that optimally respond to the evolving system conditions, thus representing an upper-bound solution that removes the myriad of institutional and geophysical factors that can cause actual operations to deviate from optimal rules ${ }^{[49]}$. The optimal policies are designed via evolutionary multi-objective direct policy search method ${ }^{[50]}$, a Reinforcement Learning approach that combines direct policy search, nonlinear approximating networks, and multi-objective evolutionary algorithms. The policies are defined as Gaussian radial basis functions ${ }^{[51]}$ and the policy parameters are optimized using the self-adaptive Borg MOEA ${ }^{[52]}$, a combination that has been demonstrated to be effective in solving these types of multi-objective policy design problems for large-scale water systems ${ }^{[53]}$.

\section{Generation of climate scenarios}

Climate projections are obtained from the CORDEX project ${ }^{[54]}$. Specifically, we use three scenarios corresponding to RCP2.6, RCP4.5, and RCP8.5 as simulated by the MPI-ESM-LR global circulation model and dynamically downscaled by means of the RCA4 regional circulation model, which provides simulated trajectories of precipitation and temperature with a spatial resolution of $0.44^{\circ}$. We further statistically downscaled these scenarios using a time-varying quantile mapping technique to match the cumulative density function (CDF) of the RCA4 simulations over the control period (19812005) with the CDF of the observations, generating a correction function depending on the day of the year and the quantile of the distribution. The correction function is then used to unbias day by day and quantile by quantile the considered variable over the projection period (2006-2100). Lastly, the downscaled trajectories of precipitation and temperature are used as inputs to the local hydrologic models for generating streamflow projections (Supplementary Figure S4).

\section{Generation of irrigation demand scenarios}

The socio-economic scenarios used in this study were developed by ${ }^{[16]}$ through a factorial sampling of the Shared Socio-economic Pathways (SSPs). That work aggregated the SSP assumptions into six categories: socio-economics (population, GDP), changes in energy demand (transportation, building, industrial), agricultural productivity and dietary trends, fossil fuel extraction costs, renewable energy costs, and carbon capture and sequestration costs. Within each category, discrete sampling levels tied to the SSP quantification by ${ }^{[13]}$ were defined. Scenarios were generated through a full factorial combination of all sampling levels across all uncertainty categories. Three long-term $\mathrm{CO} 2$ price trajectories were used to simulate different levels of global emissions reductions: a no-tax business as usual case, a low-tax case (\$10/tonne of CO2 in 2020, increasing at $5 \%$ per year), and a high-tax case (\$25/tonne of $\mathrm{CO} 2$ in 2020 , increasing at $5 \%$ per year). Policy implementation uncertainty, as described in the Shared Policy Assumptions (SPAs, ${ }^{[15]}$ ) was also sampled. Specifically, whether a delay in the universal adoption of the $\mathrm{CO} 2$ price would occur, and the extent (geographic and level) to which LUC emissions would be priced. In total, 33,750 global change scenarios were generated and simulated using the Global Change Assessment Model (GCAM). 
GCAM is a global integrated assessment model that pairs a representation of various natural systems (primarily the climate) with representations of various human systems, including the agricultural, energy, transportation, and building sectors. GCAM was one of four models used to develop the RCPs ${ }^{[11]}$, one of five models used to quantify the SSPs ${ }^{[13]}$, and was used in the IPCC's fifth assessment report ${ }^{[12]}$. GCAM divides the world into 32 energy-economic zones, which are further sub-divided into 233 river basins, and 283 agro-ecological zones ${ }^{[10]}$. The model is modular, allowing sectors in different regions and basins to represented with varying levels of detail. Sectors and regions are linked by markets for energy and agricultural goods. This linkage allows for the incorporation of economic teleconnections in regional resource analyses. For instance, the impact of population growth or technological innovation in one region on agricultural water consumption in another can be quantified. GCAM is a partial equilibrium model, in which prices are adjusted in each simulation period such that supply equals demand for all goods in all markets in all regions. Each of the 33,750 scenarios developed by ${ }^{[16]}$ reports the production across crops in each of the 32 GCAM energy-economic zones. These data are spatio-temporally downscaled to monthly crop demands (Supplementary Figure S5) on a 0.5-degree grid using the Tethys model ${ }^{[17]}$.

\section{Generation of interdependent scenarios}

We generated an ensemble of interdependent scenarios through an a posteriori coupling of the irrigation demand scenarios with the climate projections on the basis of the 2100 radiative forcing simulated by GCAM and used as starting point for the generation of the climate scenarios. Specifically, we associated to the three RCP projections the scenarios of irrigation demands generated by a simulation of GCAM returning a value of radiative forcing in 2100 within a window of $0.2 \mathrm{~W} / \mathrm{m}^{2}$ centered in $2.6,4.5$, and $8.5 \mathrm{~W} / \mathrm{m}^{2}$, respectively (Supplementary Figure S3). Notably, none of GCAM simulations produces a forcing value compatible with the projections of RCP2.6. We therefore associate this climate projection with the irrigation demand scenarios characterized by the smallest forcing values simulated by GCAM. The coupling of climate and socio-economic projections substantially reduced the number of the irrigation demand scenarios: starting from the 33,750member ensemble, the resulting ensemble of interdependent scenario includes 2,439 scenarios.

\section{Data and Code Availability}

Data about the socio-economic scenarios produced by GCAM simulations are available on Github (https://github.com/JRLamontagne/Factorial SSP-SPA Exploration). All the data on the Zambezi River basin are from the Zambezi River Authority (ZRA) and were collected during the DAFNE project (http://dafne-project.eu/). They are protected by a nondisclosure agreement with ZRA. Because the model contains such sensitive data on hydropower plant characteristics, water demand, and streamflow, they cannot be made public. The code for generating the figures can be found on Github (https://github.com/mxgiuliani00/ZRB gcam).

\section{References}

41. G. Lindström, B. Johansson, P. M., M. Gardelin and S. Bergström, "Development and test of the distributed HBV-96 hydrological model," Journal of Hydrology, vol. 201, no. 1-4, pp. 272288, 1997.

42. C. Funk, P. Peterson and M. Landsfeld, "The climate hazards infrared precipitation with stations - a new environmental record for monitoring extremes," Scientific Data, vol. 2, 2015.

43. N. Chaney, J. Sheffield, G. Villarini and E. Wood, "Development of a high-resolution gridded daily meteorological dataset over sub-Saharan Africa: spatial analysis of trends in climate extremes," Journal of Climate, vol. 27, no. 15, pp. 5815-5835, 2014.

44. J. Matos, A. Schleiss, J. Mertens and B. Wehrli, "Developing an open-source database for the Zambezi river basin," in Water Storage and Hydropower Development for Africa, Marrakesh (Morocco), 2015. 
45. R. Soncini-Sessa, A. Castelletti and E. Weber, Integrated and participatory water resources management: Theory, Amsterdam: Elsevier, 2007.

46. A. Celeste and M. Billib, "Evaluation of stochastic reservoir operation optimization models," Advances in Water Resources, vol. 32, no. 9, pp. 1429-1443, 2009.

47. ZAMCON, "Integrated water resources management strategy and implementation plan for the Zambezi River Basin," Zambezi River Basin Commission, Harare, 2016.

48. A. Castelletti, F. Pianosi and R. Soncini-Sessa, "Water reservoir control under economic, social and environmental constraints," Automatica, vol. 44, no. 6, pp. 1595-1607, 2008.

49. F. Bertoni, A. Castelletti, M. Giuliani and P. Reed, "Discovering dependencies, trade-offs, and robustness in joint dam design and operation: An ex-post assessment of the Kariba dam," Earth's Future, vol. 7, p. 1367-1390, 2019.

50. M. Giuliani, A. Castelletti, F. Pianosi, E. Mason and P. Reed, "Curses, tradeoffs, and scalable management: Advancing evolutionary multi-objective direct policy search to improve water reservoir operations," Journal of Water Resources Planning and Management, vol. 142, no. 2, 2016.

51. L. Busoniu, D. Ernst, B. De Schutter and R. Babuska, "Cross-entropy optimization of control policies with adaptive basis functions," IEEE Transactions on Systems Man Cybernetics, vol. 41, no. 1, pp. 196-209, 2011.

52. D. Hadka and P. Reed, "Borg: An auto-adaptive many-objective evolutionary computing framework," Evolutionary Computation, vol. 21, no. 2, pp. 231-259, 2013.

53. M. Giuliani, J. Quinn, J. Herman, A. Castelletti and P. Reed, "Scalablemultiob- jective control for large-scale water resources systems under uncertainty," IEEE Transactions on Control Systems Technology, vol. 26, no. 4, pp. 1492-1499, 2018.

54. F. Giorgi, C. Jones and G.R. Asrar, "Addressing climate information needs at the regional level: the cordex framework," World Meteorological Organization (WMO) Bulletin, vol. 58, no. 3, 2009.

\section{Acknowledgements}

The authors would like to thank Barbara Benigni, Federica Bertoni, Flannery Dolan, and Sebastian Raimondo for their contribution in developing initial numerical experiments. This work has been partially supported by DAFNE under H2O20 framework programme of the Europen Union, grant number 690268.

\section{Competing Interests.}

427 The authors declare that they have no competing financial interests.

\section{Author contributions}

$M G, J L, A C$ designed the research and writing of the paper. MG and JL conducted the numerical experiments and lead the data analysis. $\mathrm{MH}$ and PR contributed in analysis of results and writing of the paper.

\section{Correspondence}

433 Correspondence and requests for materials should be addressed to Andrea Castelletti (email: 434 andrea.castelletti@polimi.it). 


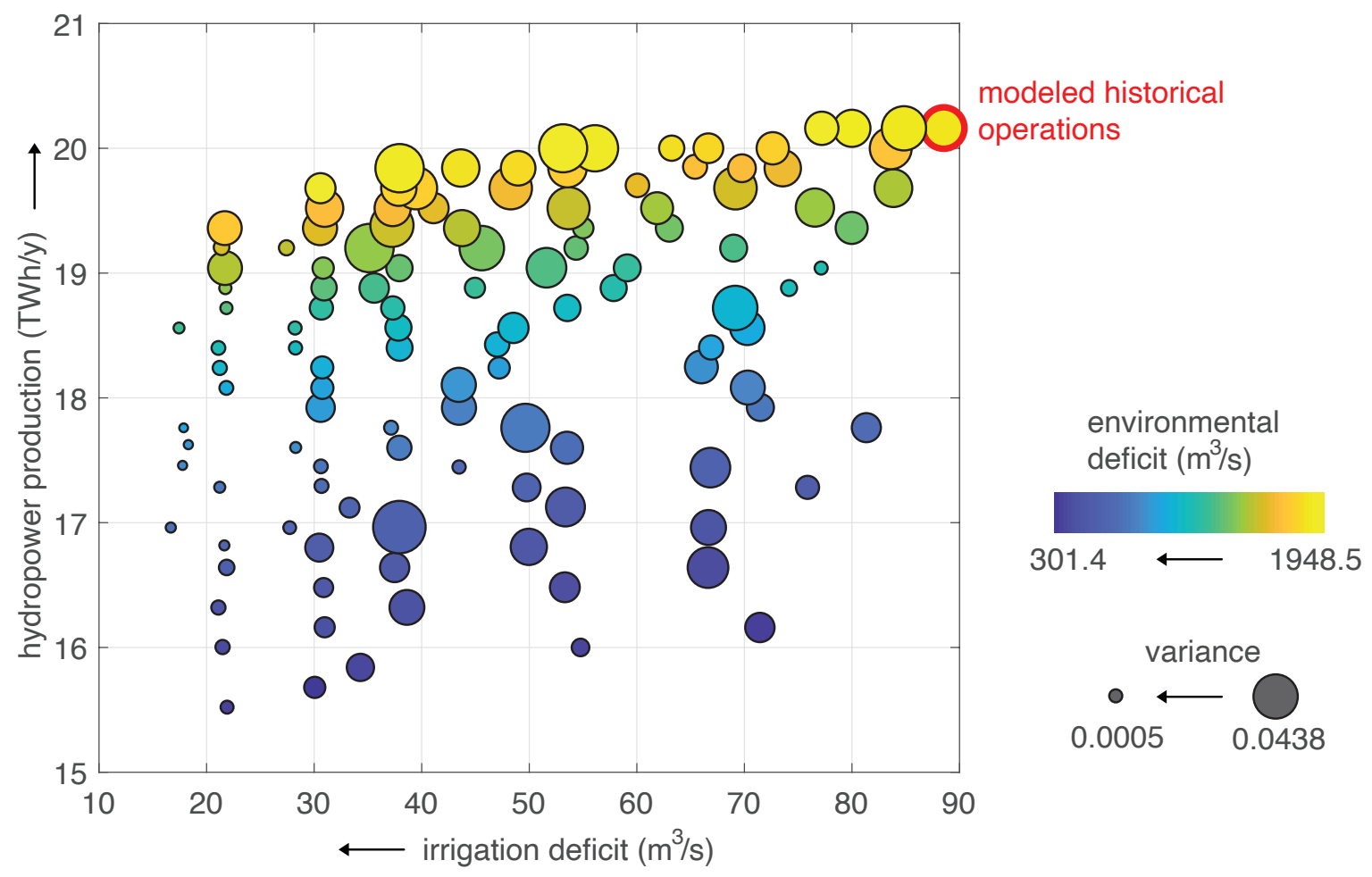

Figure S1: Performance of 120 alternative policies for the operations of dams and irrigation diversions in terms of irrigation deficit ( $x$ axis) and hydropower production ( $y$ axis); the environmental deficit is represented by the color of the circles, where the best solution is a blue circle; the size of the circles is proportional to the variance of the irrigation deficit, with the best solution represented by a small circle. Black arrows indicate the direction of increasing preference, with the ideal solution represented by a small, blue circle in the top-left corner of the figure, while each circle represents a different tradeoff between the four objectives. The circle with the red edge represents the best solution in terms of hydropower production, with this policies assumed to model the historical operations of the system.

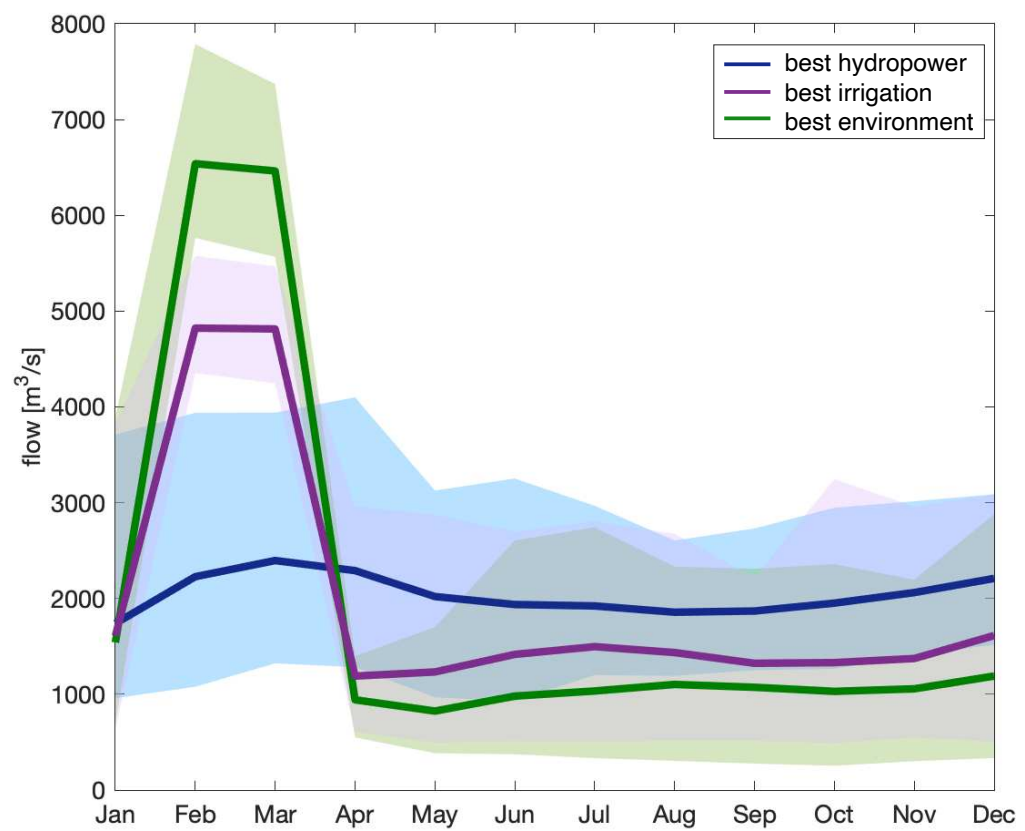

Figure S2: Simulated trajectories of average flow in the Zambezi River Delta under three different 
453

environment solution (green). The shaded areas refer to the variability over the 20 years of simulation horizon.

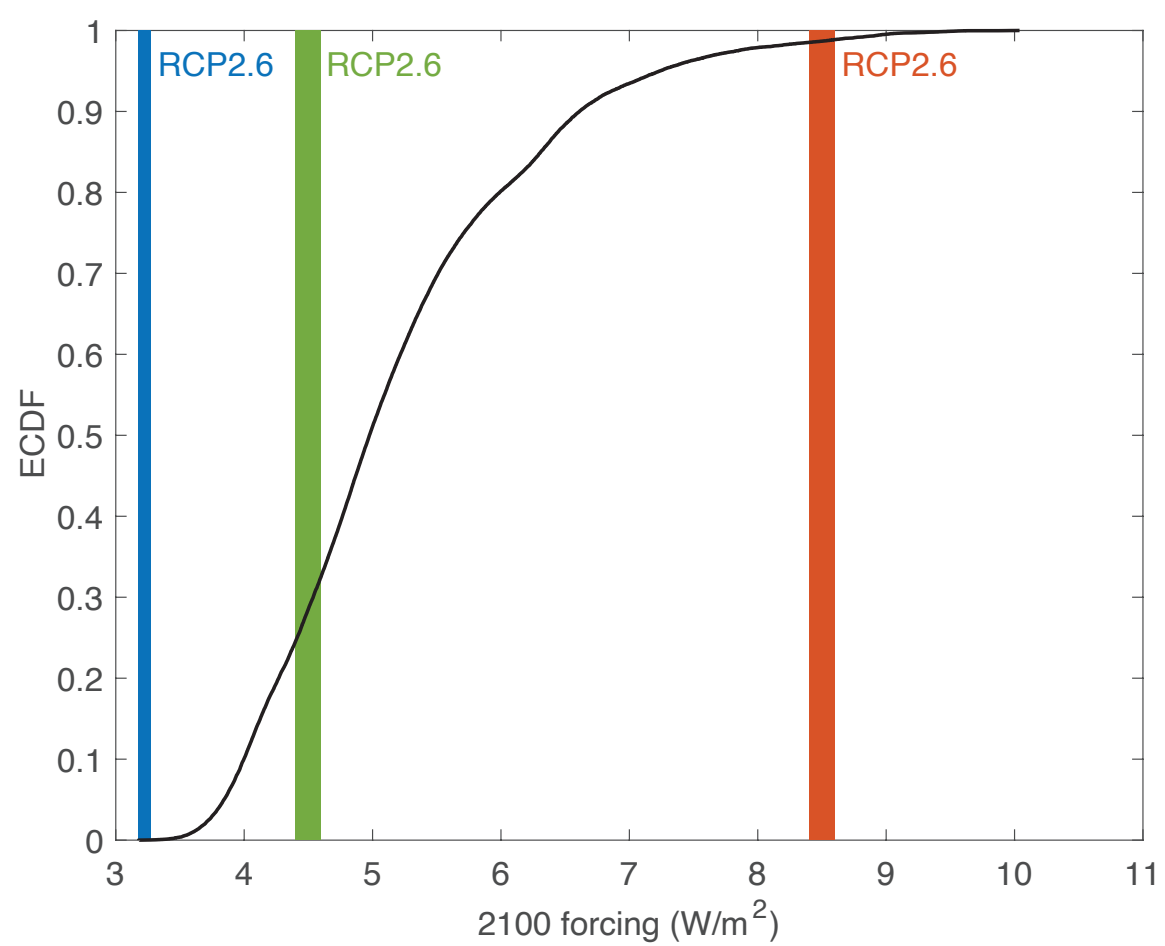

Figure S3: Coupling of irrigation demand scenarios with the climate projections on the basis of the 2100 radiative forcing simulated by GCAM. We used a window of $0.2 \mathrm{~W} / \mathrm{m}^{2}$ centered in the forcing values characterizing the RCP projections (i.e., $2.6,4.5$, and $8.5 \mathrm{~W} / \mathrm{m}^{2}$ ).
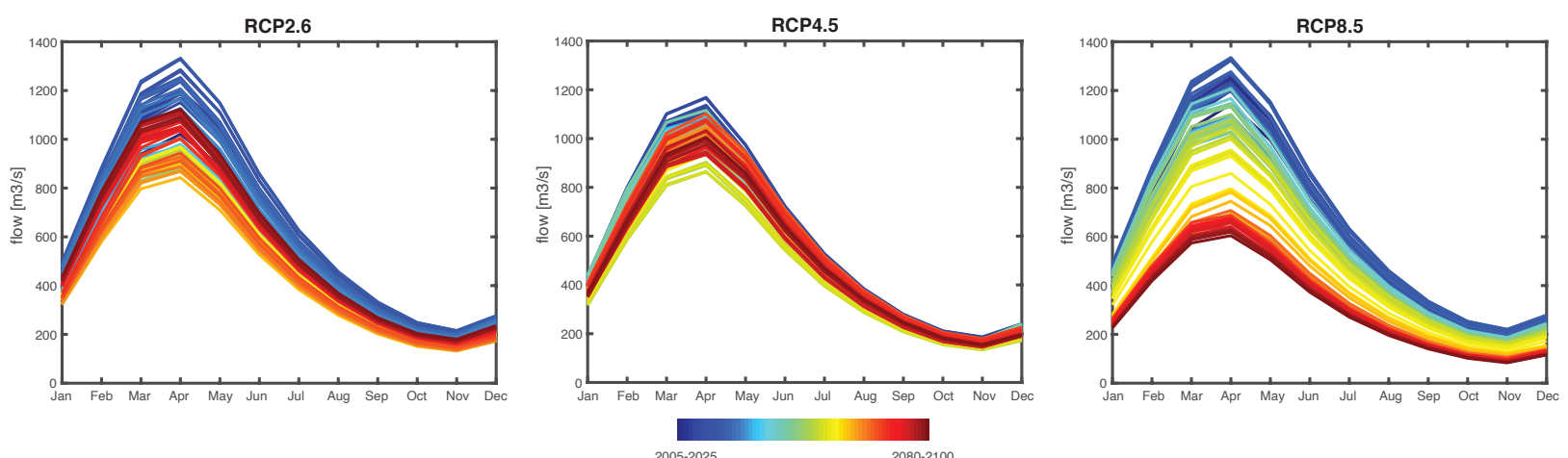

Figure S4: Trend analysis of the projected Zambezi River monthly streamflow at Victoria Falls station over the time horizon 2005-2100: the average is computed by means of a moving window that includes data over consecutive years, with the window progressively shifted ahead to identify longterm trends. In the figure, each line represents a 20 -years moving average, from the 2005-2025 (blue) to the 2080-2100 (red) time horizons. 


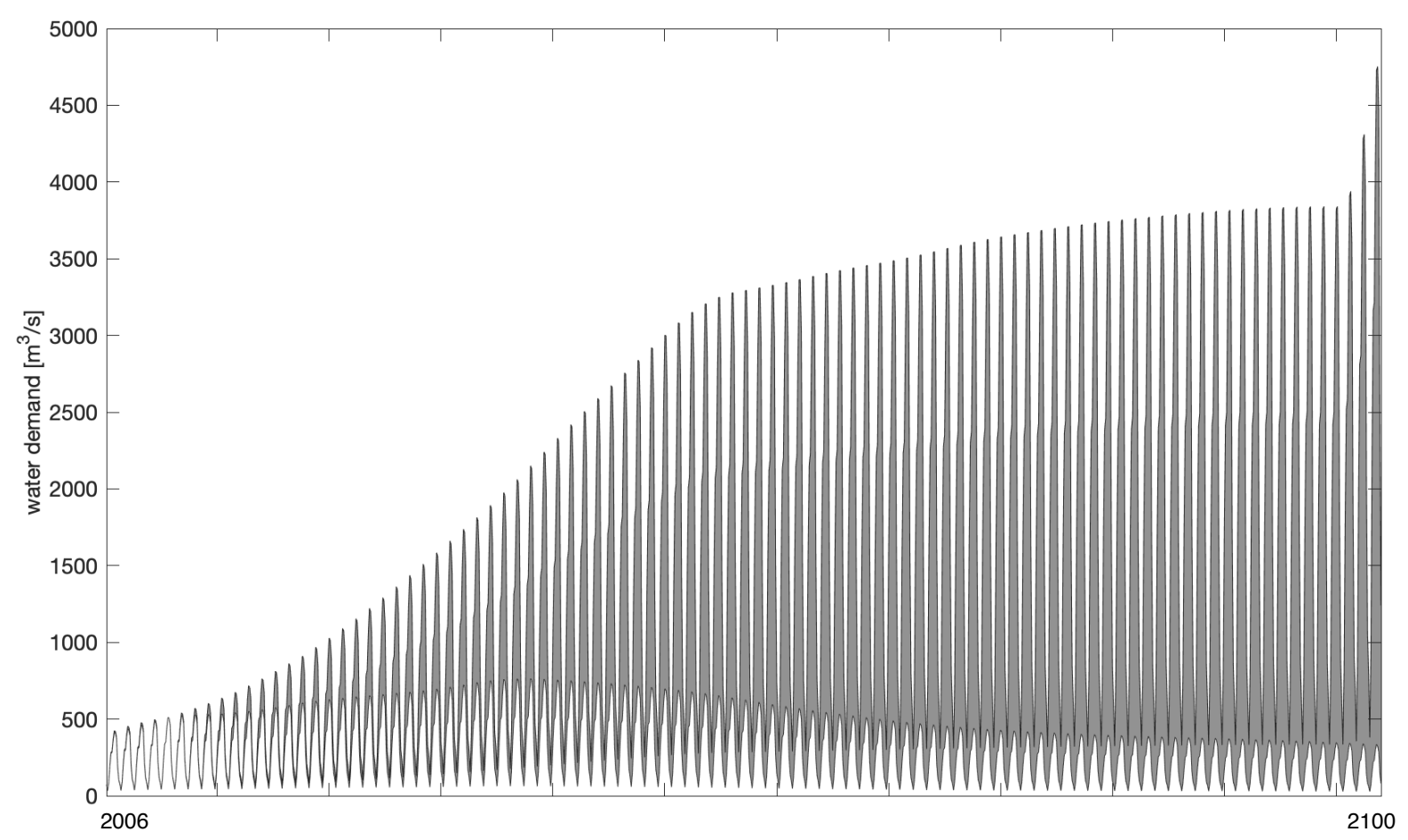

466

Figure S5: Projected irrigation demands aggregated for the seven districts of the Zambezi River Basin. The gray shaded area represents to the variability across the considered 2,439 interdependent scenarios.

(a)

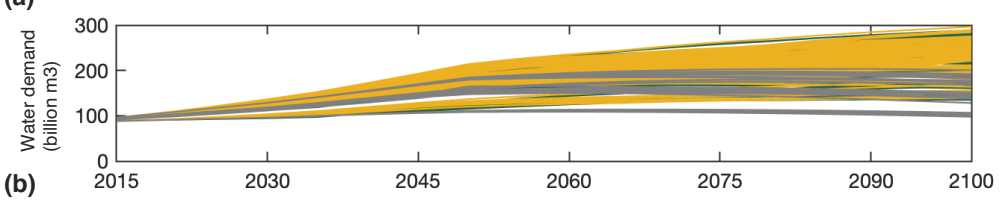

(b)
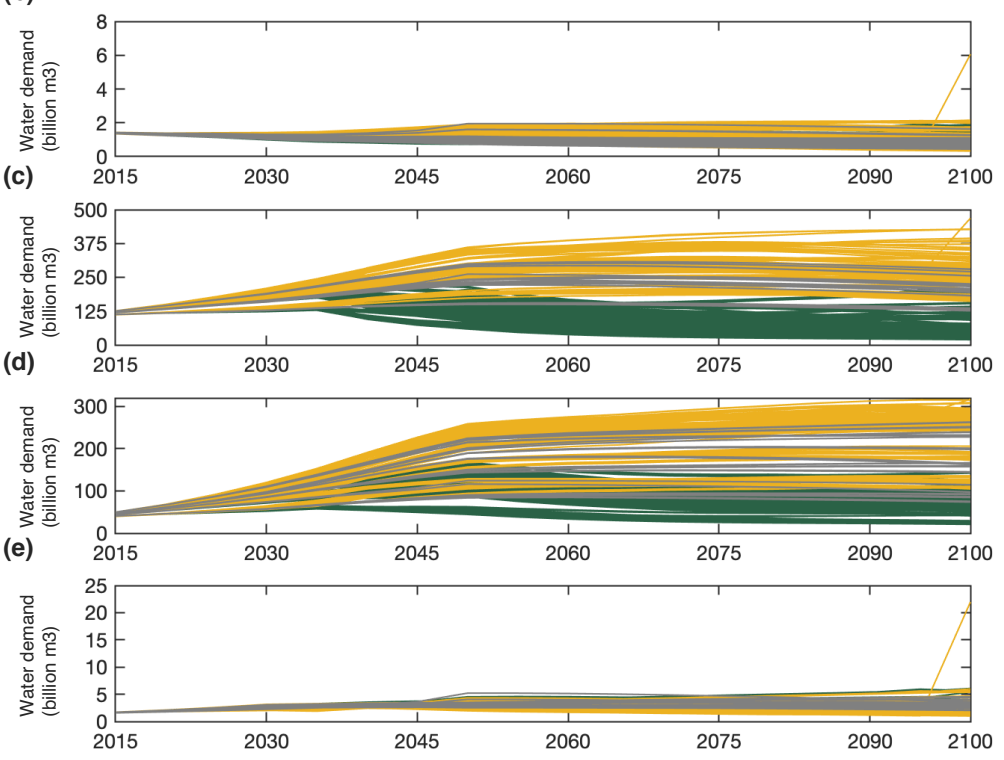
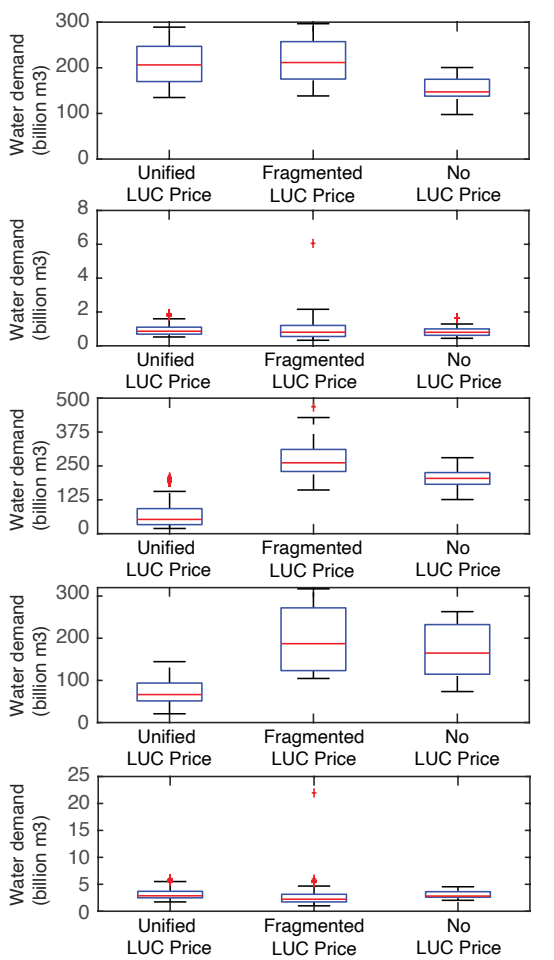

Figure S6: Projected irrigation demands in scenarios with universal (green), fragmented (yellow), and no (gray) LUC price for Northern Africa (a), Eastern Africa (b), Western Africa (c), Southern Africa (d), and South Africa (e). The box plots visualize the statistical distribution of 2100 water demands. 


\section{Figures}

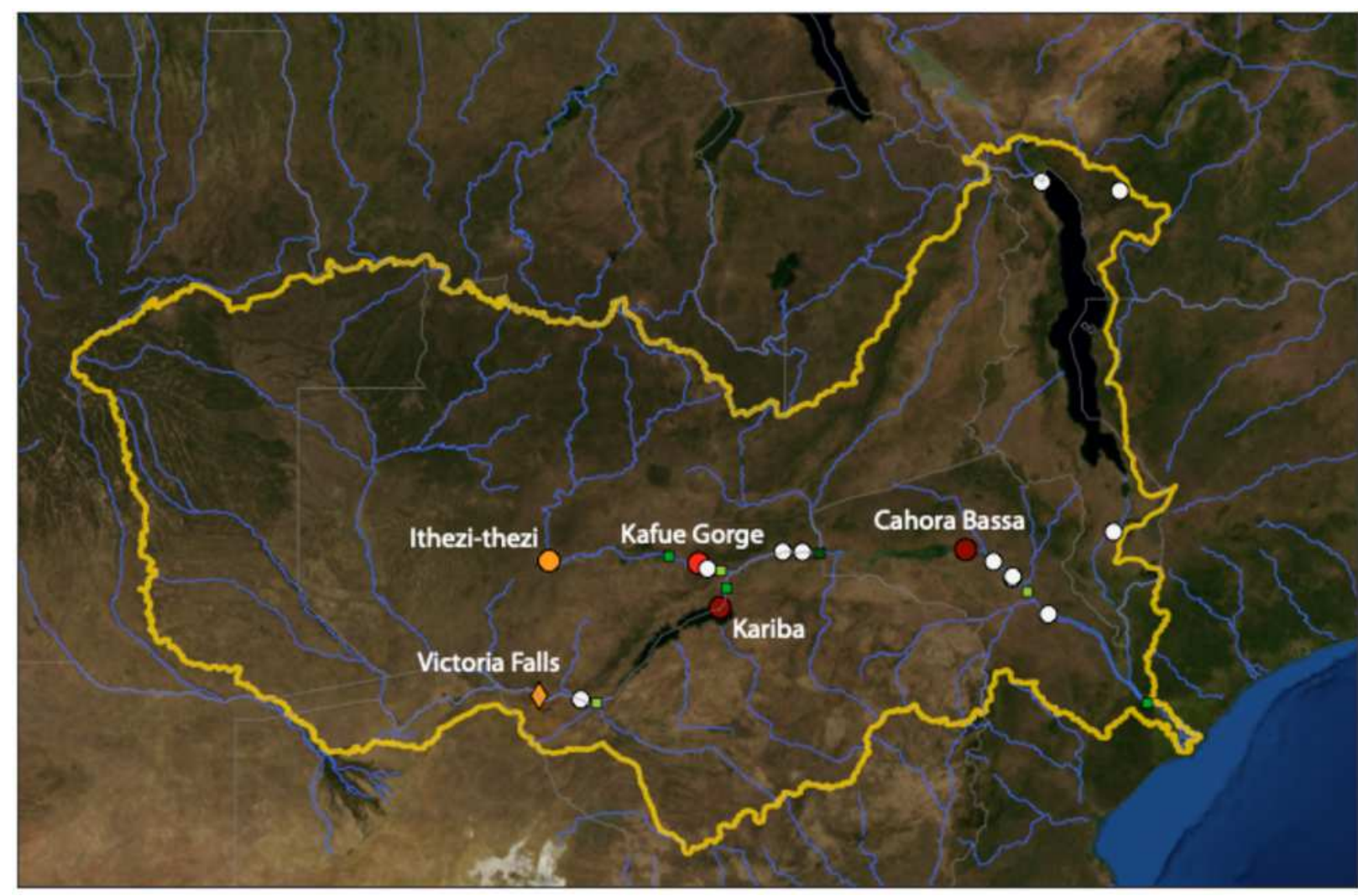

Hydropower plants

$\bigcirc$ Existing Storage

O Planned Storage

$\diamond$ Run-of-the-river

Installed Capacity

- 100-500 MW

- 501-1500 MW

- 1501-2500 MW

Irrigation districts

ㅁ $1-10 \mathrm{~m}^{3} / \mathrm{s}$

- $11-50 \mathrm{~m}^{3} / \mathrm{s}$

- $51-100 \mathrm{~m}^{3 / \mathrm{s}}$

\section{Figure 1}

Locations of dams and irrigation districts in the Zambezi River basin. Four dams and six power plants are currently in operations for a total installed capacity of 5,500 MW, while existing irrigated areas cover about 182,000 ha. Planned hydropower reservoirs will provide $8,400 \mathrm{MW}$ of additional power capacity. 

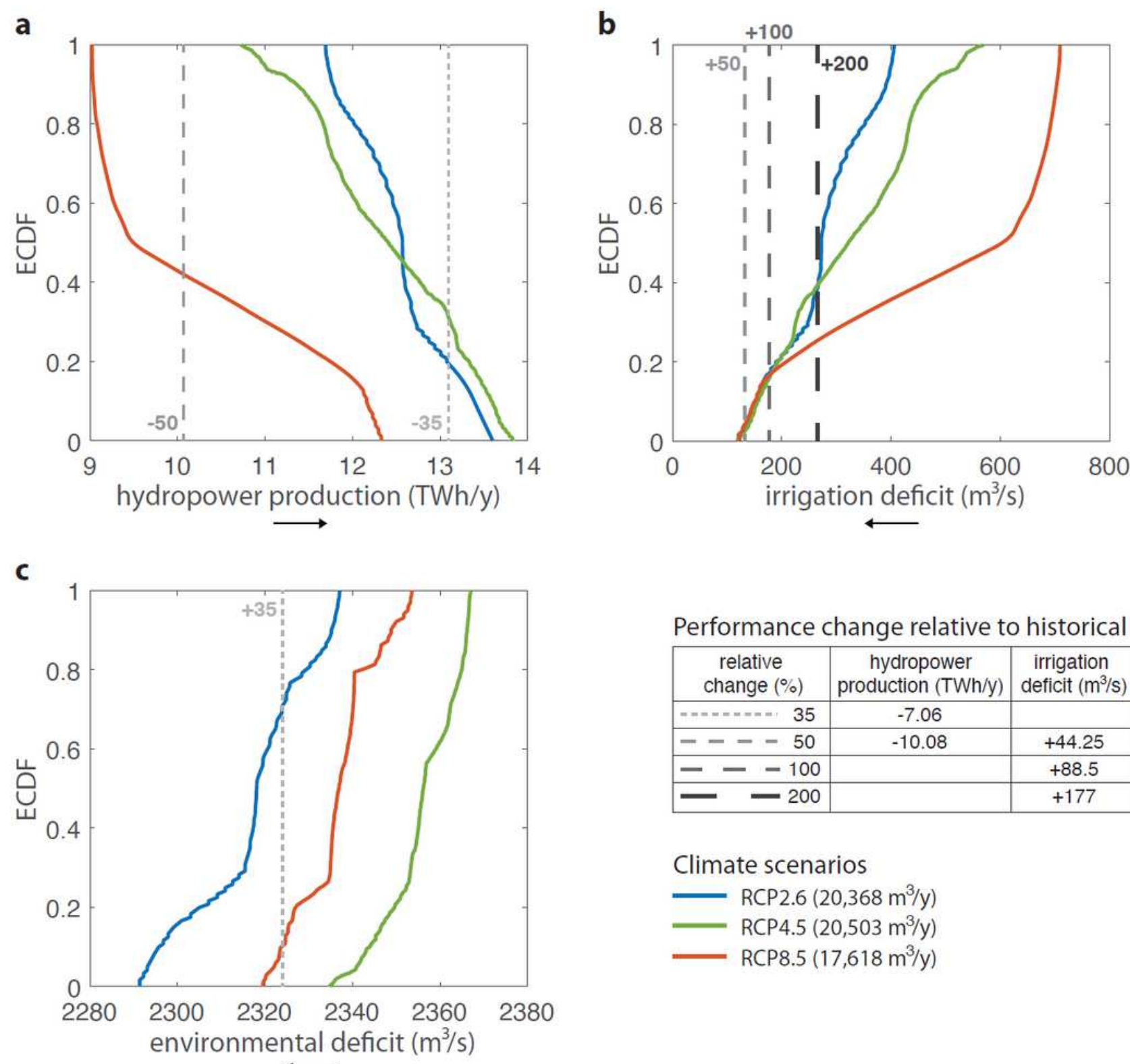

Performance change relative to historical period

\begin{tabular}{|c|c|c|c|}
\hline $\begin{array}{c}\text { relative } \\
\text { change (\%) }\end{array}$ & $\begin{array}{c}\text { hydropower } \\
\text { production }(\mathrm{TWh} / \mathrm{y})\end{array}$ & $\begin{array}{c}\text { irrigation } \\
\text { deficit }\left(\mathrm{m}^{3} / \mathrm{s}\right)\end{array}$ & $\begin{array}{c}\text { environmental } \\
\text { deficit }\left(\mathrm{m}^{3} / \mathrm{s}\right)\end{array}$ \\
\hline-35 & -7.06 & & +602 \\
\hline----50 & -10.08 & +44.25 & \\
\hline---100 & & +88.5 & \\
\hline$-\quad-200$ & & +177 & \\
\hline
\end{tabular}

Climate scenarios

$-\operatorname{RCP} 2.6\left(20,368 \mathrm{~m}^{3} / \mathrm{y}\right)$
RCP4.5 $\left(20,503 \mathrm{~m}^{3} / \mathrm{y}\right)$
$\operatorname{RCP} 8.5\left(17,618 \mathrm{~m}^{3} / \mathrm{y}\right)$

\section{Figure 2}

Future system vulnerabilities. Empirical Cumulative Distribution Functions of the uncertain attainment of the local ZRB objectives estimated via simulation of the modeled historical ZRB operations over the ensemble of interdependent climate and socio-economic scenarios (hydropower production (a), irrigation deficit (b), and environmental deficit (c), while the variance objective is not shown due to its limited sensitivity to the considered scenarios). Black arrows indicate the direction of increasing preference for each objective. The color of the ECDF lines marks the different climate scenarios; values in brackets report the projected average annual flow entering the river basin. The dashed vertical lines represent the degradation of performance relative to the historical one (see Supplementary Figure S1). 
a

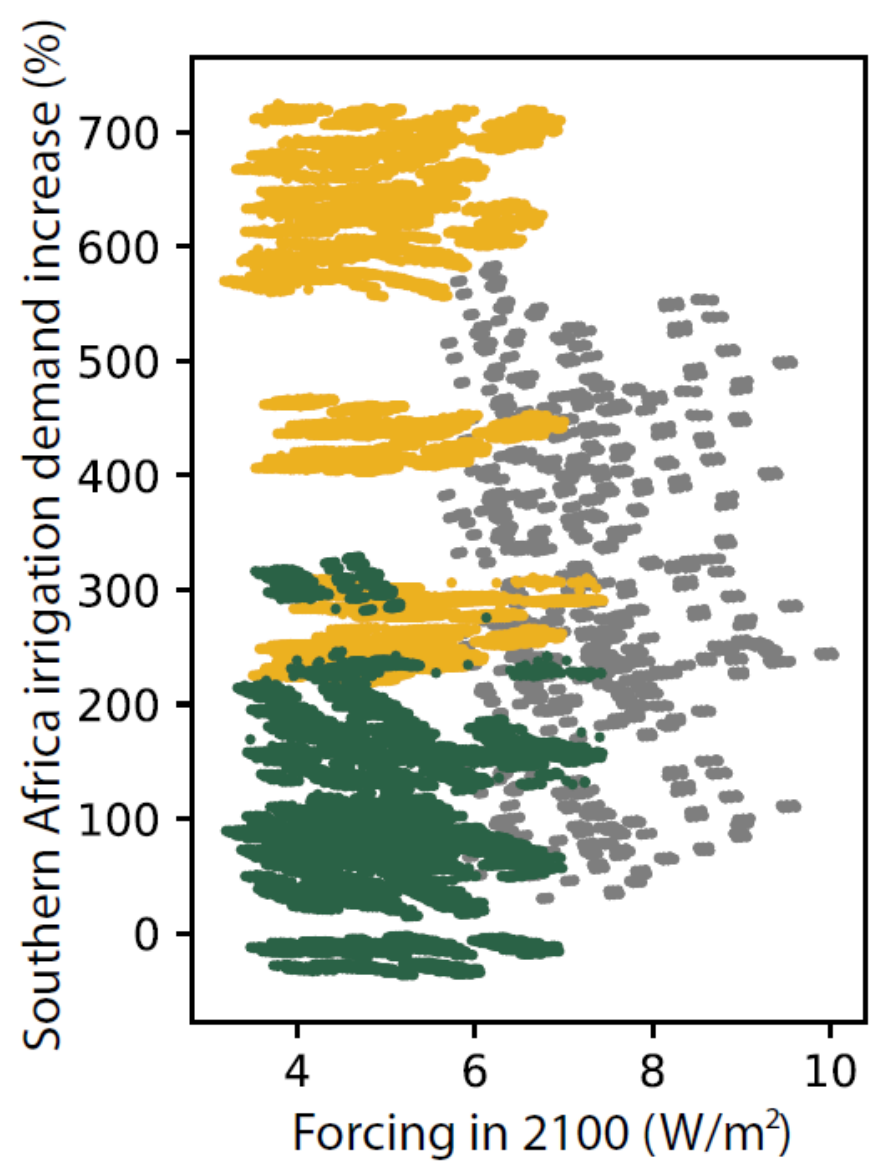

b

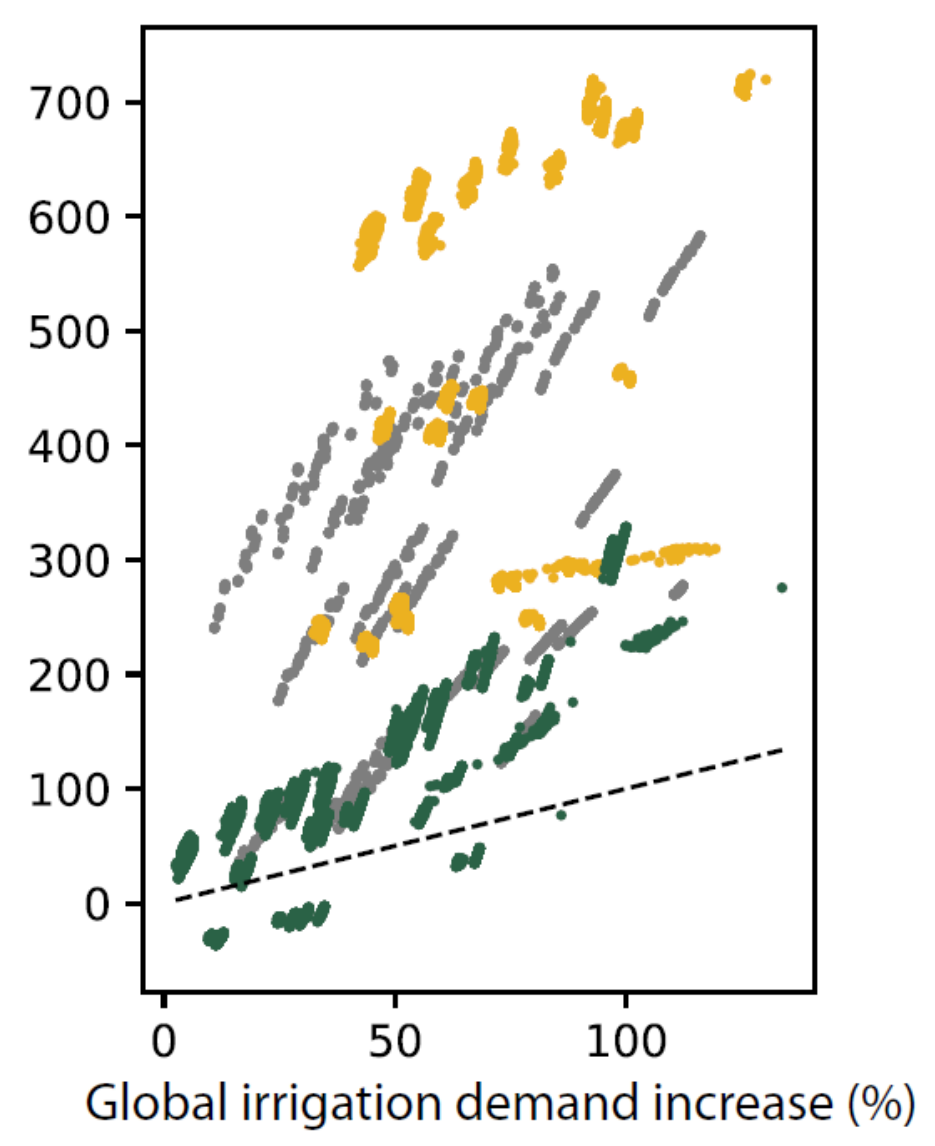

Figure 3

Analysis of socio-economic scenarios generated by GCAM. a, Scatterplot between end of century radiative forcing and irrigation demand growth relative to 2005 for the Southern Africa region. $b$, Scatterplot between global and Southern Africa irrigation demand growth relative to 2005 (the black dashed line is the 1:1 reference). Colors represent alternative policies of Land Use Change (LUC) emission price: gray points are scenarios with no emission price, green with universal LUC price, and yellow with fragmented LUC price (i.e., wealthy countries pay a higher LUC emission price than developing ones due to their strong attempts to curb LUC emission). 

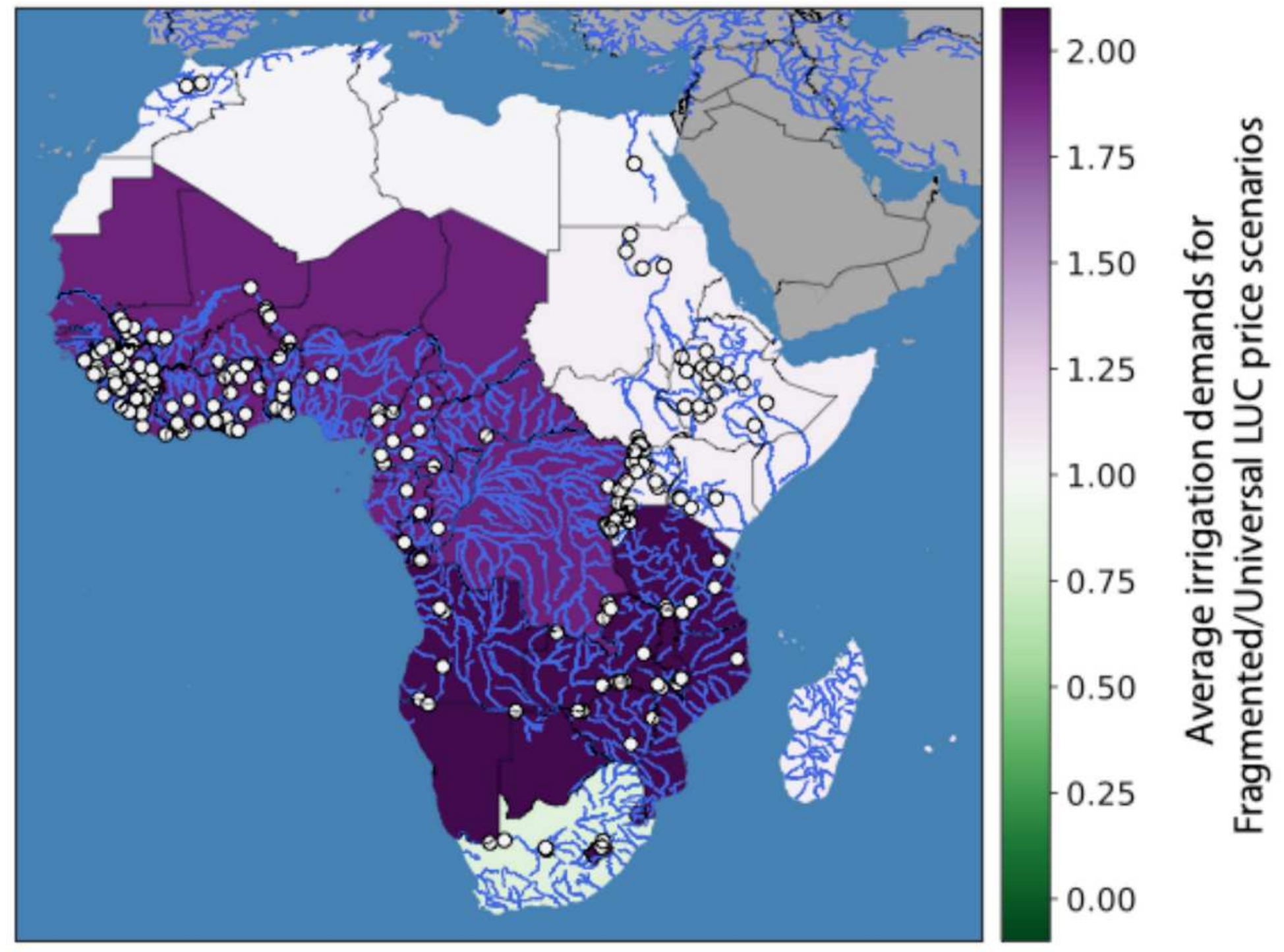

\section{Figure 4}

Projected vulnerabilities of African regions. The map shows African countries colored according to the ratio of average 2005-2100 irrigation demands projected by GCAM for scenarios with fragmented LUC price over the one of scenarios with universal LUC price. The white circles indicate the locations of future hydropower reservoirs and dams extracted from [35].

\section{Supplementary Files}

This is a list of supplementary files associated with this preprint. Click to download.

- ZRB.zip 